\title{
Sexualidade, gênero e identidade: questões para a psicanálise
}

\section{Sexuality, gender and identity: questions for psychoanalysis}

O objetivo deste ensaio é analisar a forma pela qual as noções de sexualidade, gênero e identidade colocam questões para a psicanálise, na medida em que problematizam formas de subjetivação presentes em sua prática discursiva. Considerando a análise de Foucault a respeito da formação do dispositivo da sexualidade e a discussão empreendida por Butler sobre o problema da identidade nas discussões de gênero, pretende-se situar o lugar do complexo de Édipo na constituição do sujeito em psicanálise e a crítica de Freud à moralização da sexualidade na experiência moderna. Finalmente, a partir das noções de vulnerabilidade e de despossessão de si, retomam-se os conceitos psicanalíticos de desamparo e de feminilidade com o objetivo de pensar a importância de um pensamento da alteridade para a prática psicanalítica.

Palavras-chave: Sexualidade, gênero, identidade, alteridade

*1 Université de Paris, CRPMS, F. 75013 (Paris, França). 
O objetivo deste ensaio é abordar as problemáticas da sexualidade e do gênero, observando suas formações e desenvolvimentos ao longo da modernidade até o momento contemporâneo, e indicar algumas questões lançadas a partir dessas problemáticas para a psicanálise enquanto discurso e prática clínica. Sua organização seguirá dois momentos distintos: o primeiro analisará como a sexualidade se constituiu como campo a partir do século XVIII na história do Ocidente, e o segundo discutirá em que medida a noção de gênero, empregada posteriormente nesse debate, retoma, por uma relação estreita, a concepção psicanalítica de sexualidade para relançar a discussão em direção a uma problematização da identidade. A ordem de distribuição desses momentos seguirá a orientação geral em torno da qual esse debate se deu, de modo que, atravessando os problemas de sexualidade, gênero e identidade, buscar-se-á apresentar como, a partir da segunda metade do século XX, foram desenvolvidas algumas interpelações importantes em relação à psicanálise.

\section{A sexualidade moderna e sua constituição como ciência}

A publicação do primeiro volume de História da sexualidade, de Michel Foucault, em 1976, pela editora Gallimard, na França, constituiu um marco bastante significativo para pensar as relações da psicanálise com a sexualidade. Com efeito, depois das manifestações de maio de 1968 e, sobretudo, com a publicação em 1972, de Anti-Édipo, de Deleuze e Guattari, o discurso psicanalítico já havia sido objeto de crítica e de discussão no cenário acadêmico e social francês. No 


\section{ARTIGOS}

entanto, ainda que o livro de Foucault possa ser concebido na continuidade desse movimento crítico, como um dos desdobramentos possíveis das discussões em torno da sexualidade e da liberdade sexual da virada dos anos 1960 e 1970, ele constitui, de fato, uma ruptura em relação a essa perspectiva, como veremos a seguir, de modo que a interlocução de Foucault com a psicanálise tomará uma outra direção.

É preciso dizer, em primeiro lugar, que antes de abordar a problemática da sexualidade em 1976, e desde que anunciara o seu projeto de realizar uma genealogia do poder no Ocidente, Foucault havia analisado a problemática do corpo a partir de uma história do nascimento das prisões, onde o que estava em jogo era a maneira pela qual as formas de vigilância se relacionaram com as formas de punição na história recente (Foucault, 1975). Com a publicação do livro Vigiar e punir, em 1975, o filósofo francês sistematizara toda uma teoria sobre as relações de poder, esboçada por ele desde 1971 em seus cursos no Collège de France, em que o corpo se tornara espaço privilegiado do exercício do poder (Foucault, 1973/1994a, pp. 468-470).

Com efeito, na passagem do sistema de suplícios do poder soberano das monarquias para um sistema disciplinar de distribuição do poder, constitui-se, segundo Foucault (1975, p. 34) doravante uma microfísica do poder. Das fábricas às escolas, passando pelos hospitais, pelo exército e pela família, os mecanismos de poder na modernidade teriam como objetivo atingir a materialidade dos corpos por um sistema de controle e vigilância, tal como delineado no projeto do Panóptico de Bentham (Foucault, 1975, pp. 175-177). Se o que estava em questão no livro de Foucault de 1975 era de fato a constituição de uma anatomia-política dos corpos, em 1976, essa mesma genealogia do poder o conduziria a analisar a formação de uma biopolítica das populações (Foucault, 1976, pp. 182-183). Menos a dimensão do indivíduo-corpo e mais a dimensão do indivíduo-espécie, essa seria a perspectiva adotada pelo autor nos estudos sobre a sexualidade, uma vez que se tornaria possível identificar em torno dessa problemática uma estratégia global do exercício de poder sobre as populações (Foucault, 19751976/1997, pp. 223-224).

Outro aspecto definidor do projeto foucaultiano da história da sexualidade em 1976 é uma concepção positiva das relações de poder (Foucault, 1976, pp. 16-17). Se considerarmos a entrevista dada por Foucault em 1977, As relações de poder se passam no interior dos corpos, vamos identificar que esse projeto estava presente no pensamento de Foucault desde a década 1960, quando analisara a problemática da loucura (Foucault, 1977/1994b, pp. 229-230). Uma vez que em seus estudos sobre $A$ história da loucura na 
Idade Clássica, Foucault havia identificado desde o século XVII uma distribuição do pensamento ocidental entre a razão e a desrazão (a partir do cogito cartesiano) e a exclusão da loucura através da constituição dos Hospitais gerais - por meio do decreto real de 1656 na França e do internamento dos loucos junto com os miseráveis e criminosos, numa verdadeira condenação social da ociosidade (Foucault, 1972, pp. 56-91) —, o filósofo francês pretendia, pela mesma chave de leitura, estudar dois domínios da sexualidade: uma sexualidade oficial ou autorizada e uma sexualidade interdita. Como se a partir da divisão binária entre razão e desrazão fosse possível analisar uma série de outros domínios da experiência moderna do pensamento, Foucault pretendia aplicar o mesmo método que empregara para estudar a loucura à sexualidade. Todavia, com a formalização da genealogia enquanto método (Foucault, 1971/1994c, pp. 136-156), seria definida uma outra concepção em relação ao poder, esta não mais regida pela negatividade (exclusão, interdição e proibição), mas pela positividade (produção, injunção e multiplicação). $O$ poder sobre a sexualidade antes de dizer "não", constitui-se como uma verdadeira afirmação positiva, de modo que, em relação ao sexo, o problema não deve se orientar a partir daquilo que se exclui ou das formas pelas quais a exclusão é realizada, mas pelo que, através do poder, representa um verdadeiro "sim" à sexualidade (Foucault, 1976, pp. 20-22).

É pelo estudo, portanto, das formas de regulação das populações, isto é, de uma biopolítica, e da maneira pela qual o poder se produz positivamente no Ocidente, que Foucault empreendeu essa história da sexualidade na modernidade que constitui o primeiro volume de sua obra, $A$ Vontade de saber. Foi pelo estudo, finalmente, que foram delineadas algumas linhas de força da constituição do que denominou dispositivo da sexualidade, e isso a partir de três direções distintas.

A primeira é que, no nível do discurso, antes de silenciar e excluir as formas de saber sobre a sexualidade, a modernidade produziu uma verdadeira injunção para falar sobre isso (Foucault, 1976, pp. 25-49). Da pastoral católica à instituição da família, passando pela escola, pela clínica médica e pela literatura libertina, o Ocidente exigiu essa passagem do sexo para o discurso, de modo que, na institucionalização da confissão católica, nas arquiteturas e nos documentos institucionais das escolas, na produção de todo um método clínico - orientado em torno da codificação clínica do "fazer falar", dos postulados de uma causalidade geral e de um princípio etiológico latente, da criação de um método interpretativo e da medicalização da sexualidade 


\section{ARTIGOS}

- observou-se menos uma restrição discursiva em relação ao sexo e mais uma multiplicação.

No que concerne às práticas da sexualidade, igualmente (Foucault, 1976, pp. 50-67). Ora, se no antigo regime canônico e civil do direito, até o século XVII, os ditos desvios em relação à sexualidade eram considerados todos, sem especificação, transgressões ao princípio jurídico e religioso do matrimônio - isto é, tudo o que ultrapassava esse registro era considerado, de uma forma global, infrações no domínio da sexualidade —, a partir do século XVIII, passou-se por todo regime de especificações, devido sobretudo ao desenvolvimento da clínica médica, de modo que a antiga figura do libertino se transformou na personagem do perverso, com seus respectivos nomes e descrições psiquiátricos (Foucault, 1976, p. 60).

Se o Ocidente testemunhou uma injunção discursiva e uma implantação perversa da sexualidade na individualidade dos corpos, foi através da constituição de uma ciência da sexualidade que uma vontade de saber se delineou definitivamente em tornou do sexo na história moderna (Foucault, 1976, pp. 70-98). Em oposição a uma modalidade de arte erótica presente em sociedades antigas ou em sociedade ditas não ocidentais, ou pelo menos não inteiramente ocidentalizadas, as sociedades ocidentais inventaram uma ciência da sexualidade, de modo que, objeto de um discurso científico, a sexualidade, por essa via, se constituiu como uma forma de sujeição dos indivíduos - sendo este o primeiro sentido do termo sujeito empregado por Foucault. Como essa genealogia do poder sobre sexualidade impõe algumas das primeiras questões para a psicanálise, é o que pretendemos abordar a seguir.

Com efeito, tradicionalmente, a psicanálise pensou a sexualidade por um ponto de vista do poder concebido como forma de repressão. Se a partir de uma discussão em torno da tradução do termo Verdrängung a comunidade psicanalítica operou um deslocamento importante em relação à compreensão daquilo que Freud (Freud \& Breuer, 1895/2002, pp. 216-217; Freud, 1915/1988a, pp. 191-203) identificou primeiramente como modalidade de resistência à análise para caracterizar, em seguida, como sendo o afastamento de determinado conteúdo psíquico da consciência e o fato de mantê-lo à distância; se com a utilização do termo recalque em vez de repressão para traduzir Verdrängung, buscou-se identificar os mecanismos psíquicos ou estruturais por meio dos quais o sujeito é atravessado por um desejo constituído pela lei (Lacan, 1957/1966a, pp. 514-518; 1960/1966b, p. 782); o que Foucault pretende demonstrar é que foi sempre a partir de um ponto de vista 
jurídico do poder que se organizou a relação entre pulsão e Verdrängung em psicanálise, independentemente se se traduz Verdrängung por repressão ou por recalque. O que se manifesta nas diferentes acepções atribuídas ao termo corresponde, na realidade, a uma concepção diferente do mecanismo das pulsões, e não a uma modificação no que tange à compreensão do poder (Foucault, 1976, p. 109). A forma pela qual se dá o exercício do poder, em ambos os casos, é sempre em psicanálise uma forma negativa, de modo que, nessa perspectiva, a tradição psicanalítica pensaria as resistências do sujeito do ponto de vista de uma defesa.

$\mathrm{Na}$ mesma direção dessa interpelação de Foucault à psicanálise, identifica-se sua crítica ao Anti-Édipo, de Gilles Deleuze e Félix Guattari. Ora, se, por um lado, a submissão do desejo à representação do triângulo edipiano - constituído entre a criança, a mãe e o pai —, tal como apresentada pelos autores, representaria uma redução da produtividade do desejo a uma estrutura moderna de familiarização, por outro, a desterritoralização, orientada por devires e territoralizações que ultrapassam em muito a estrutura de Édipo, e ainda a retomada da produtividade maquínica do inconsciente (Deleuze \& Guattari, 1972, pp. 7-14, 29-43), corresponderia apenas a uma vontade de 220 potência que, para além do negativo, enxerga na liberação da sexualidade a manifestação de formas de resistência. Todavia, para Foucault, tratar-se-ia ainda dos mesmos mecanismos de poder, previstos pelo dispositivo da sexualidade: "Esse poder justamente não tem nem a forma da lei nem os efeitos do interdito. Ele procede, ao contrário, pela multiplicação de sexualidades singulares. Ele não fixa fronteiras para a sexualidade. [...] Ele produz e fixa o disparate sexual" (Foucault, 1976, pp. 64-65).

Em segundo lugar, em relação à psicanálise, é preciso dizer que Foucault identificou em sua prática discursiva, de maneira predominante, uma continuidade entre a teoria da sexualidade e as práticas de confissão e de exigência de produção de verdades incidentes na scientia sexualis. Ora, desde os escritos sobre as psiconeuroses de defesa até o que se poderia identificar como últimos textos de Freud sobre as estruturas clínicas em psicanálise, isto é, Neurose e psicose e $A$ perda da realidade na neurose e na psicose, é sempre a partir da compreensão de uma etiologia sexual das neuroses ou, ainda, da importância da sexualidade nas formações do inconsciente que a clínica psicanalítica foi pensada (Freud, 1894/2010a, p. 3; Freud, 1896/2010b, p. 62; Freud, 1924/2010c, pp. 283-284, Freud, 1924/2010d, pp. 299-300, 303).

Se Foucault identificou na passagem das exigências da confissão pastoral para os métodos de escuta na clínica a exigência de trabalho em torno do falar 


\section{ARTIGOS}

sobre a sexualidade, é a partir de uma concepção da sexualidade como campo mesmo em torno do qual toda interpretação e medicalização do sujeito deve se dar que ele pôde afirmar: "A causalidade no sujeito, o inconsciente do sujeito, a verdade do sujeito no outro que sabe, o saber nele daquilo que ele mesmo não sabe, tudo isso pôde se desenvolver no discurso do sexo" (Foucault, 1976, p. 94).

Assim, se a psicanálise, por um lado, empregara ao longo de seu movimento, para utilizar um termo adotado por Freud (1914/2005a, p. 249), uma concepção jurídica do poder, onde a pulsão se relaciona com um mecanismo de defesa cujo estatuto é primordialmente caracterizado pela negatividade, por outro, ela só pôde se constituir como discurso e definir em torno de seu objeto inconsciente uma positividade, como forma de causalidade psíquica, sob a direção geral de um dispositivo da sexualidade.

É preciso, no entanto, se perguntar, e isso a partir de ditos e escritos posteriores de Foucault, se, desse ponto de vista, a psicanálise permanece inteiramente inscrita na tradição que identificara sob a forma de scientia sexualis ou se, diferentemente de uma ciência, a psicanálise poderia se orientar em função de uma estética da existência (Birman, 1997, p. 89), aproximando o quadro definido pela sexualidade em Freud de uma experiência erótica. Com efeito, quando se perguntara na aula de 6 de janeiro de 1982 de seu curso no Collège de France sobre $A$ hermenêutica do sujeito, em relação ao trabalho necessário do sujeito sobre si para ter acesso à verdade, no caso das antigas práticas de cuidado, e não apenas isso, mas também sobre os efeitos sobre o sujeito pelo fato de ele dizer a verdade sobre si, Foucault localizara precisamente nas elaborações de Lacan uma das formas modernas de retomada de antigas questões presentes na tradição da espiritualidade (Foucault, 1981-1982/2001, pp. 31-32). Que o sujeito como tal não tenha direito nem seja capaz de ter acesso à verdade, que, para ter acesso à verdade, seja preciso "que o sujeito se modifique, se transforme, se desloque, torne-se, em certa medida e até certo ponto, outro que não ele mesmo" (Foucault, 1981-1982/2001, p. 18), essas foram algumas das questões que Lacan colocou, na medida em que pensou a especificidade da experiência psicanalítica a partir das relações entre o sujeito e a verdade (Lacan, 1960/1966b, pp. 815-816; Lacan, 1966c, p. 864).

Seria, com Lacan (1959-1960/1986, p. 9), a experiência da psicanálise uma experiência mais próxima de uma ética do que de uma ciência? (Foucault, 1983/2015, p. 114), essa é uma questão que gostaríamos de colocar - sem necessariamente afirmar — o que seria desconsiderar o próprio 
método genealógico — que a psicanálise seria uma modalidade moderna de ars erotica.

\section{A psicanálise como crítica da sexualidade moderna}

Quando se analisa a forma pela qual a problemática da sexualidade se inscreve na obra de Freud, é preciso dizer que sua última concepção da sexualidade - ou, se se quiser, das formas pelas quais o sujeito homem ou mulher se reconhece como sujeito de uma sexualidade - se orienta a partir da referência que ele faz à citação de Napoleão: "a anatomia é o destino" (Freud, 1923/2002a, p. 121).

Com efeito, desde a formulação da segunda tópica da metapsicologia na década de 1920, Freud, nos diferentes artigos em que retomou a questão da sexualidade infantil desenvolvida incialmente na década de 1900, identificou na diferença anatômica entre os sexos o principal fator de determinação dos destinos do complexo de Édipo nas formas de subjetivação. A retomada do caso clínico do pequeno Hans e as elaborações em torno da fase fálica, conduziram-no a identificar na presença ou na ausência do pênis, enquanto órgão, as consequências psíquicas das diferenças de subjetivação no homem e na mulher, de forma que as identificações do sujeito, as relações que estabelece com os objetos e, finalmente, as modalidades de saída do complexo de Édipo, seriam determinadas pelas formas distintas de reconhecimento da castração e pelas posições subjetivas adotadas pelo homem e pela mulher diante da angústia de castração (Freud, 1923/2002b, pp. 114-116; Freud, 1923/2002a, pp. 118-119, Freud, 1925/2002c, pp. 130-132).

Da "Organização genital infantil" a "Algumas consequências psíquicas da diferença anatômica entre os sexos", passando por "A dissolução do complexo de Édipo", é essa concepção geral a propósito da diferença sexual que orienta a teoria freudiana, de modo que relacionar a sexualidade à anatomia seria uma das formas possíveis pelas quais o ideal da ciência permaneceria de maneira predominante na obra de Freud (1933/2004, pp. 267-268).

No entanto, se atentarmos para alguns de seus textos das duas décadas precedentes, pode-se igualmente contemplar a presença de uma outra perspectiva. Mesmo que os "Três ensaios sobre a teoria da sexualidade", de 1905, possa ser, sob muitos aspectos, aproximada a uma obra científica sobre a sexualidade, é nesse mesmo texto que Freud (1905/2006, pp. 98-104, $107-111,133-137,146-151)$ identifica a presença de uma sexualidade nas 


\section{ARTIGOS}

crianças e, ao mesmo tempo, atribui à sexualidade, de forma geral, o caráter de infantilidade. Ora, se por um lado Freud descreve a inscrição da sexualidade no corpo da criança a partir de todo um desenvolvimento possível onde as pulsões se orientam através de zonas erógenas para, num momento ulterior, atingir a genitalidade, esse investimento do corpo não se dá sem se caracterizar por uma autonomia das funções sexuais em relação à anatomia, como manifesta sua tese de uma sexualidade perverso e polimorfa (Poli, 2007, p. 13). Com efeito, como se observa nas discussões em torno da tradução do termo Trieb, traduzido ora por instinto - correspondendo a Instinkt - ora por pulsão, identifica-se em Freud a não correspondência entre a sexualidade da psicanálise e a sexualidade do discurso médico, baseado numa anatomia patológica (Foucault, 1963/2000, pp. 123-149).

Além disso, é preciso dizer, que, nesse mesmo ensaio, Freud (1905/2006, p. 82) apresenta uma distinção importante entre a sexualidade dos antigos e a sexualidade dos modernos. A saber, que enquanto para os antigos a sexualidade se ordenava em função das intensidades, pouco importando a natureza objetal das formas de satisfação, para os modernos, mais importante do que as intensidades seriam os objetos através dos quais a sexualidade seria vivida. Com efeito, a constituição de uma "moral sexual "civilizada" estaria na origem das "doenças nervosas dos tempos modernos" (Freud, 1908/2005b, pp. 198-199, 203-205), de modo que, ao postular a existência de uma sexualidade perverso e polimorfa no coração da subjetividade e ao indicar que, em relação à pulsão, o que há de mais variável se situa no nível do objeto (Freud, 1915/1988b, p. 170), Freud manifestadamente apresenta uma psicanálise crítica da sexualidade moderna. Longe de se reduzir às determinações de um desenvolvimento biológico da libido, bem como às formas pelas quais o Ocidente realizou a "moralização" da experiência erótica, a experiência psicanalítica deveria permitir uma circulação da sexualidade, operada por movimentos de desidentificação e potencializada por experimentações criativas (Poli, 2007, p. 18).

Menos sob a forma psicológica do desejo, como caracterizou Foucault (1978/2011, pp. 389-390), haveria na psicanálise um espaço de abertura ao que, entre os corpos, se manifesta como prazer? Seria possível, por essa via, pensar o segundo sentido do termo sujeição, proposto por Foucault, quando ele se caracteriza como forma de resistência? (Foucault, 1976, pp. 90-92).

Talvez, entre os autores da tradição psicanalítica, Lacan tenha sido o que mais contribuiu para a desconstrução, para empregar um termo caro a Derrida (1967, pp. 25-26), do complexo de Édipo. Em primeiro lugar, foi Lacan 
quem, ao conceber um inconsciente estruturado como uma linguagem (Lacan, 1953/1966d, p. 269), empreendeu uma leitura de Édipo a partir da noção de estrutura. Isto é, segundo o autor, entre o bebê e seus pais, haveria muito mais a circulação de um objeto como atributo de valor e a caracterização das figuras parentais como funções simbólicas do que uma coincidência naturalizante entre o objeto psíquico e um determinado órgão — se quisermos falar do primado do falo em Freud.

Se tomarmos as elaborações desenvolvidas por Lacan no seminário de 1957-1958, intitulado As formações do inconsciente, vamos encontrar ali a caracterização de diferentes momentos de incidência da estrutura de Édipo na constituição subjetiva da criança (Lacan, 1957-1958/1998, pp. 179-212), e isso depois de ele ter desenvolvido no seminário sobre As psicoses, entre 1955 e 1956, e no importante artigo "De uma questão preliminar a todo tratamento possível da psicose", os conhecidos Esquemas R e I para pensar a incidência da metáfora paterna, o significante representante do pai, o Nome-do-Pai, na passagem do triângulo imaginário (bebê, mãe e falo) para o triângulo simbólico (sujeito barrado, lei e objeto a) (Lacan, 1955-1956/1981, pp. 349-363; Lacan, 1958/1966e, pp. 553-554, 571-575). Em 1957-1958, com

224 efeito, Lacan retoma essa passagem necessária entre os campos do imaginário e do simbólico, onde no centro havia localizado a banda de realidade, mais tarde denominada de banda do real, para falar dos diferentes tempos de Édipo, fundamentais para a constituição do sujeito em psicanálise.

No primeiro tempo de Édipo, portanto, na relação entre a criança e a mãe, encontra-se a circulação de um objeto de valor que é o falo, de modo que, se por um lado a criança atribui à mãe a presença desse objeto, dessa espécie de atributo ou qualidade, por outro ela pretende ela mesma se tornar o falo, alienando-se ao desejo da mãe. É nessa fase que se dá, segundo Lacan, a constituição do narcisismo, de modo que, pela circulação do objeto fálico entre a mãe e a criança, esta última permanece assujeitada ao desejo daquela (Lacan, 1957-1958/1998, pp. 181-183, 188-190, 192). Se a criança se constitui como eu imaginário, a mãe, por sua vez, não aparece senão para a criança sob a forma de imagem especular. É essa configuração, com efeito, que podemos observar no caso do pequeno Hans, quando Hans atribui não apenas a objetos e a coisas inanimadas a presença do falo, mas também à própria mãe, que o confirma (Freud, 1909/1999, pp. 94-95).

O segundo tempo de Édipo, para Lacan (1957-1958/1998, pp. 183-186, 192), é caracterizado por um deslocamento do objeto fálico. Com efeito, e num primeiro momento, é precisamente o ir e vir da mãe que permite 


\section{ARTIGOS}

à criança a simbolização da alteridade, de modo que a mãe não deve ser complemente idêntica à criança - ela não é, nos termos de Lacan, completa em relação à criança e nem a criança, inversamente, deve ser completa em relação à mãe. Pelo aparecer e desaparecer da mãe, a criança percebe o simples fato de que sua mãe pode desejar alhures. $O$ falo não pertence, portanto, à criança nem se confunde com seu modo de ser. Ora, se por sua palavra a mãe manifesta que seu objeto de desejo não se reduz nem se identifica com o ser da criança, é em torno da introdução de outra personagem nesse cenário que a interdição do incesto será efetivamente realizada.

No terceiro tempo de Édipo, quando o falo passa a ter um estatuto simbólico, o pai aparecerá como aquele capaz de promover a castração, logo a destituição do lugar de satisfação imaginária ocupada pela mãe, mas também é ele quem permite, na função de doador, como assinala Lacan, a assunção da criança à posição de sujeito — ainda que, dada a castração, essa posição se manifeste como a de um sujeito barrado (Lacan, 1957-1958/1998, pp. 193-196). É essa operação simbólica de Édipo, pela circulação do falo entre as funções materna e paterna, que dará lugar à constituição do sujeito de desejo, para Lacan, de modo que longe de simplesmente fazer equivaler a operação da função fálica presente no complexo de Édipo à diferença anatômica entre os sexos, o psicanalista francês define a anatomia apenas como suporte imaginário para a construção do fantasma. É, de fato, pela constituição simbólica do sujeito e pela forma como o seu desejo será estruturado por uma determinada relação com o objeto perdido, o objeto $a$, que a entrada e a saída de Édipo terão uma função determinante na relação fantasmática do sujeito com aquilo que Lacan (1957-1958/1998, pp. 238-239, 245-247) denominou de real.

Assim, enquanto abordara a importância de Édipo na constituição do sujeito, Lacan redefinira as relações entre o corpo e o imaginário pela introdução do estatuto simbólico da fala e da linguagem nas formações do inconsciente, mantendo por essa mesma via, no horizonte das possibilidades de subjetivação em psicanálise, o complexo edipiano indicado por Freud. A partir dos anos de 1970, seja com o seminário Ou pior, de 1971-1972, seja com o seminário Mais, ainda, de 1972-1973, não será nem Édipo o romance familiar do indivíduo moderno, nem o falo o único determinante para as orientações do gozo. Se em 1970, no seminário $O$ avesso da psicanálise, Lacan (1969-1970/1991, pp. 110-111, 140-153) propusera toda uma série de lições onde a figura do pai, enquanto mestre, apareceria como castrada - o que deveria indicar para o sujeito uma forma de subjetivação para além do complexo de 
Édipo —, nos dois seminários a partir de 1971, postulará, concernente aos modos de sexuação, a existência de um gozo suplementar ao gozo fálico e irredutível à sua lógica universalizante (Lacan, 1971-1972/2011, pp. 25-48, 111-121; Lacan, 1972-1973/1975, pp. 61-82).

Ora, se do lado homem, em sua fórmula da sexuação, o gozo fálico depende necessariamente da existência de ao menos um cuja função fálica não tem incidência estruturante - o pai da horda — , para que em seguida todos os homens sejam submetidos à ordem do falo, do lado mulher, não existindo mulher em relação à qual o falo não opera, por outro lado ela permanece não complemente determinada por essa função. A mulher, na fórmula de Lacan, é não toda, portanto, inscrita na ordem fálica (Lacan, 1972-1973/1975, pp. 30-36, 67-71). Haveria, por essa via, a possibilidade de pensar um gozo específico da mulher, um gozo irredutível à universalidade do falo, e que se manifesta, em Lacan, como gozo Outro, gozo essencialmente determinado pela contingência e abertura à singularidade.

Com a problematização das formas de gozo a partir de uma discussão em torno das formas pelas quais os sujeitos se constituem como homens ou mulheres, Lacan radicalizaria na psicanálise uma perspectiva crítica em 226 relação à centralidade do falo, de modo que o discurso psicanalítico se deslocaria efetivamente da centralidade anatômica para a determinação simbólica da sexualidade. É precisamente por essa via que a problemática do gênero incide na psicanálise, de modo que, com as reflexões de Judith Butler, as interpelações ao discurso que tem sua origem em Freud se deslocam do domínio da sexualidade para o domínio do gênero, sendo uma e outra faces de uma mesma problemática a respeito da constituição de identidades em relação ao campo do desejo.

\section{A problemática do gênero e o pensamento da identidade}

Foi em 1987 que Judith Butler publicou, pela Columbia University Press, sua tese de doutorado, defendida em 1984 e intitulada Sujeitos de desejo. Com efeito, de maneira bastante ambiciosa, o livro pretendia traçar o que teria sido a recepção francesa ao longo do século XX do pensamento de Hegel, de maneira geral, e mais especificamente, de que forma a noção de sujeito teria sido investida pela problemática do desejo. Ora, seria, portanto, questão para a filósofa, retomar os diferentes autores do cenário francês em que o pensamento de Hegel teve incidência, passando por Kojève e Hyppolite, 


\section{ARTIGOS}

num primeiro momento, para, depois de percorrer a obra de Sartre, incidir nos autores que os anglo-saxões reuniram sob a expressão teoria francesa contemporânea, isto é, Derrida, Lacan, Deleuze e Foucault.

Embora tenha, no decorrer desse livro, assinalado em diversas passagens como o estatuto eminentemente negativo do desejo em Lacan, isto é, o desejo concebido como opacidade, fora um verdadeiro motor no discurso psicanalítico para a subversão do sujeito e para o seu descentramento (Butler, 1987, pp. 186-204), quando retomou os enunciados de Lacan em seu livro posterior sobre os Problemas de gênero, em 1990, Butler (1999/1990, pp. 45-49, 55-73) realizou uma crítica profunda da tradição psicanalítica, uma vez que, segundo a autora, a psicanálise teria sido um dos discursos precursores na modernidade de uma matriz heteronormativa para definir a identidade de gênero.

Com o desenvolvimento de Lacan em torno da diferença sexual, a psicanálise não contribuiria senão para atribuir um estatuto hierárquico de poder ao falo na constituição psíquica dos sujeitos e nas formas de organização do gozo, de forma que se o lado masculino da sexuação em Lacan seria marcado por uma relação positiva entre a subjetividade e uma modalidade fálica do gozo, do lado feminino, a dita abertura para o gozo Outro só poderia constituir uma experiência negativa da sexualidade, a qual não prescreve nada mais que a realidade de uma falta ou de uma ausência (Butler, 1990/1999, pp. 60-61). A formação dos sujeitos no lado mulher - se considerarmos a descrição de um gozo Outro em Lacan que só é capaz de se enunciar pela via de um suplemento ou de uma alteridade quase não conceituada - justificaria a permanência de uma hierarquia entre os sexos na psicanálise, mesmo que Lacan tenha tentado descolar a noção de sexualidade da perspectiva anatômica presente em Freud, baseada na superposição do pênis ao falo e no estatuto privilegiado da presença e da atividade masculinas.

No entanto, embora essa leitura apareça de maneira evidente como uma crítica à perspectiva lacaniana de compreensão do Édipo, ela não é apresentada sem a defesa de duas teses importantes no mesmo livro, Problemas de gênero, que relançarão o debate da autora com a psicanálise para outra direção, de modo que a problemática de gênero e sua relação com o discurso psicanalítico ganhará doravante novos destinos possíveis.

A primeira tese significativa apresentada por Butler (1999/1990, pp. 9-11) nesse livro é que a distinção entre sexo e gênero não coincide com a tradicional passagem apreciada pelos estruturalistas da teoria francesa, que tem sua origem no pensamento de Lévi-Strauss, do estado de natureza para o estado de cultura. 
Se, no início de seu ensino, Lacan indicará precisamente a importância do campo simbólico para definir aquilo que permite a passagem do indivíduo animal para a dimensão do sujeito humano - o que fora retomado por Althusser (1964/1993, pp. 27-33) para definir precisamente o objeto da psicanálise —, em seus últimos textos e seminários, igualmente, Lacan (1979/1987, pp. 33-35; 1975-1976/2005, pp. 116-118) não pensará o sujeito da psicanálise por outra via senão sob a forma de um "falaser" (parlêtre), assujeitado à determinação do gozo do Outro e de sua corporeidade, "alíngua" (lalangue). A passagem da natureza para a cultura ou o que faz do sujeito um sujeito humano, em Lacan, é precisamente o fato de ele ser um ser de linguagem, sendo o campo do simbólico um operador central na constituição das subjetividades.

No entanto, segundo Butler, essa distinção entre natureza e cultura aplicada para as discussões de gênero desconhece um elemento fundamental na análise histórica da sexualidade e que consiste precisamente no fato de que o argumento da naturalidade do sexo, investido pelo discurso biológico ou pela retórica da anatomia, não é nada mais do que o resultado de um pensamento da cultura (Butler, 1999/1990, pp. 27-34). Retomando a definição do 228 dispositivo da sexualidade empreendida por Foucault, ela vai dizer que se o gênero é uma construção da sociedade, o sexo é igualmente um produto da cultura. Ou seja, não há em torno do sexo qualquer naturalidade biológica e toda suposta evidência em relação a esse domínio sustentada por um discurso anatômico corresponde, na realidade, a estratégias de poder que recorrem à legitimidade de um discurso dito científico para justificar imposições normativas.

Assim, se a sexualidade, para Foucault, como desenvolvemos, é uma invenção moderna, o sexo, longe de se manifestar como o que haveria de mais primitivo e natural, na medida em que se refere a uma simples experiência do instinto, só pode ser definido em função do cruzamento de uma série de procedimentos de saber-poder. Dizer que o sexo é natural ou produto de uma natureza é se utilizar da suposta legitimidade do discurso biológico para justificar a imposição de uma concepção de sexualidade que se define culturalmente pela forma de um pensamento binário e de uma heteronormatividade (Butler, 1999/1990, pp. 69-70).

A segunda tese importante proposta pela autora diz respeito especificamente à problemática do gênero e à forma pela qual essa problemática incide política e filosoficamente numa discussão sobre as identidades. Ora, se para Butler (1999/1990, p. 70) o movimento feminista, bem como os movimentos 


\section{ARTIGOS}

contestatórios do que denominou de heterossexualidade compulsória, colocou historicamente em questão as imposições de um modo binário e heterossexual para pensar o sexo e o gênero, seria preciso contestar igualmente a própria necessidade de referir a sexualidade dos sujeitos a um pensamento da identidade.

Como assinalou Joel Birman (2018, pp. 144-153), enquanto o movimento feminista nas décadas de 1950 e 1960 contribuiu para a modificação da configuração familiar, onde a desigualdade de direitos e de funções na família reproduzia um pensamento social fundado na estrutura do patriarcado, o movimento homossexual, sobretudo entre os anos de 1965 e 1970, contra uma sexualidade reduzida ao casal e à monogamia, defendeu a liberdade de escolha em relação aos objetos e a reivindicação de direitos equivalentes. No entanto, considerando essa nova definição da gramática do desejo, foi, de fato, o movimento dos transgêneros, a partir dos anos 1980, que colocou efetivamente em questão a problemática do gênero, de modo que foi a contestação da própria noção de identidade que se tornou objeto de debate.

Seja pela recusa das normas impostas pela filiação — com a adoção de um novo nome - , seja pela abdicação dos destinos dados pela anatomia - com a possibilidade de mudança real no corpo - , os transexuais realocaram o paradigma do autoengendramento do sujeito no centro da discussão de gênero. Pela via da nomeação no domínio do simbólico e pela modificação do corpo em sua constituição biológica, o que o sujeito transexual produziu na contemporaneidade foi a possibilidade de empreender uma recriação de si, baseada eminentemente na categoria de desejo (Birman, 2018, p. 149).

A forma pela qual Butler retoma esse debate aponta não apenas para a necessidade jurídica de reedificar uma identidade representativa capaz de justificar e valorizar a existência de outras formas de subjetivação, a que corresponderiam modalidades identitárias para além da lógica binária ou heteronormativa, mas também para a possibilidade de definir, em relação à sexualidade, um domínio de experiências em que justamente a noção de identidade é colocada em questão. Seria por uma desconstrução da relação necessária e fundante entre sexo, gênero e identidade, que a autora, desde sua tese de doutorado até seus livros mais recentes, se esforçaria por pensar o estatuto político da alteridade no vivente, na medida em que, aberto ao outro, o sujeito é essencialmente formado por aquilo que o destitui (Butler, 1999/1990, pp. 189-190).

Se sexualidade é justamente o nome desse domínio, onde, investido por saberes, poderes e formas de dominação, se manifesta ao sujeito uma relação necessariamente mediada pela presença do outro, o outro não deve ser aquilo 
que restitui ao sujeito sua identidade, mas sim, e necessariamente, aquilo que diante do qual o sujeito se encontra exposto a uma dimensão essencial de alteridade. $\mathrm{O}$ que está em jogo no encontro com o outro, nessa perspectiva, é a despossessão do sujeito em relação a si (Butler, 2004, pp. 27-29), e a experiência do impasse em representar a si mesmo pela via da identidade (Butler, 2005, pp. 41-43).

Por esse ponto de vista, se quisermos relançar a série de interpelações que as problemáticas de sexualidade e de gênero impõem à psicanálise, é preciso dizer que a retomada do discurso psicanalítico por Butler é testemunha de que o campo central por meio do qual a psicanálise pensou o conceito de inconsciente em Freud e a subversão do sujeito em Lacan não foi outro senão o do desejo. Esse domínio insubmisso à representatividade das identidades e irredutível a toda e qualquer norma de uma heterossexualidade compulsória permanece precisamente como sendo o lugar onde as subjetividades modernas são confrontadas com esse campo de indeterminação da experiência e que no discurso de Freud aparece como desamparo (Birman, 1999, pp. 162-166).

Se foi no dispositivo da sexualidade que Foucault identificara a formação 230 moderna de uma sociedade que confessa e de subjetividades assujeitadas a um funcionamento positivo do poder que impõe uma injunção a dizer, uma distribuição perversa da sexualidade e, finalmente, uma concepção da experiência erótica atravessada pelo discurso científico, é no mesmo campo da sexualidade que se impõe a afirmação de uma experiência não complemente submissa às formas normativas do desejo. Manifestando aquilo que do sujeito permanece como índice de vulnerabilidade, no caso de Butler, ou expressando a indeterminação daquilo que Freud identificara com a noção de desamparo, a experiência da sexualidade, na medida em que se desenvolve no horizonte do encontro do sujeito com o outro, permite a afirmação radical de um pensamento da alteridade, irredutível a toda identidade.

\section{Considerações finais}

De maneira predominante, como vimos, a psicanálise em Freud, por um lado, abordou a problemática da sexualidade e sua importância na determinação do psiquismo a partir da referência masculina, em que é pela presença ou pela ausência do falo que se determina o modo de constituição dos sujeitos de desejo. Como encontramos no final do texto de Freud sobre "A organização 


\section{ARTIGOS}

genital infantil", de 1923, sob o primado do falo, essa constituição se orienta em função de uma polaridade entre masculino e feminino, de modo que do lado masculino se encontram as dimensões do sujeito, da atividade e da possessão do pênis, enquanto do lado feminino se identificam a figura de um objeto, o modo de operação da passividade e, finalmente, a definição de uma órgão negativo, a vagina, cuja função não seria outra senão alojar $o$ pênis (Freud, 1923/2002b, p. 116). Por essa via, com efeito, o modo de subjetivação feminino, ou aquilo que em psicanálise se chamou de feminilidade, só pôde aparecer sob a forma de uma negatividade ou de uma ausência, como assinalou Joel Birman (2001, pp. 218-223). Se a castração é um rochedo diante do qual toda análise chega ao fim (Freud, 1937/2010e, pp. 52-55), ao positivar a feminilidade para além de suas formas negativas, Birman (1999, pp. 10-11; 2001 p. 244) pretende levantar o véu dessa experiência e demonstrar em que consiste o solo fundamental da experiência psicanalítica.

Ora, se o registro do falo faz referência às pretensões de domínio de uma racionalidade que se orienta a partir da totalização e da universalidade de um modelo de desejo, o feminino deve ser um domínio da sexualidade onde se torna possível a manifestação daquilo que resiste e não se inscreve nesse projeto universal. É, com efeito, a dissolução dessa perspectiva, em que a relação do sujeito consigo mesmo e com os outros é mediada pela ordem fálica, aquilo a que a noção psicanalítica de castração faz referência, de modo que não seriam apenas as mulheres as formas de subjetivação submetidas à castração, mas igualmente os homens. E quando Birman (1999, pp. 11-12; 2001, p. 240) pretende positivar a categoria de feminilidade não se trata de forma alguma de pensar uma forma de subjetivação onde a referência ao falo permanece no horizonte da gramática de desejo; isso porque ser ou ter o falo só poderia corresponder à superioridade daquele que o detém - manifesta sob a forma da arrogância masculina -, e não ser ou não ter o falo faria alusão apenas à dimensão da inferioridade feminina - manifesta sob a forma da inveja do pênis.

O que estaria em questão, de fato, na feminilidade em psicanálise, para Birman, é o modo pelo qual a angústia da castração se torna comum a toda e qualquer forma de sexuação, uma vez que ela se situa justamente no centro da experiência dos sujeitos com a sexualidade, onde a dimensão do encontro com o outro conduz à referência fundamental do desamparo. De modo que "se o ofício de psicanalisar implica conduzir as subjetividades a uma modalidade específica de desfalicização, denominada por Freud de experiência de castração", a noção psicanalítica de feminilidade "seria uma outra maneira de se referir a isso" (Birman, 1999, pp. 12-13). Confrontado com esse campo da 
experiência sexual, que no limite da representação manifesta o que na psicanálise se apresenta como imponderável e indizível, o sujeito em análise aposta na abertura possível daquilo que, para além do automatismo da repetição, imposto pela gozo fálico, autômaton, o conduz para o que é acaso e contingente, tiquê (Lacan, 1964/1973, pp. 53-54).

Efetivamente, é a assunção subjetiva da experiência de castração o que condensa a especificidade do discurso e da prática psicanalíticas, na medida em que, referida à sexualidade, ela se dirige para esse campo de abertura e alteridade que constitui a feminilidade (Birman, 2001, p. 240). Por essa via e contra o modelo fálico e universal do pensamento da identidade sexual, a experiência psicanalítica se define como afirmação de um espaço fundamental de produção da diferença na constituição dos sujeitos, no interior do qual, para além do modelo científico de conhecimento da sexualidade, abre-se um campo contingente de experimentação, que, irredutível à representação, se recusa à adoção de toda e qualquer identidade.

Se o que define a psicanálise é, portanto, a relação do sujeito com um domínio da experiência em que ele mesmo se encontra descentrado e atravessado por uma condição de despossessão e vulnerabilidade, é essa possi-

232 bilidade de devir outro de si mesmo, isso porque em estreita relação com a alteridade, que se encontra definida no horizonte da experiência psicanalítica. Ora, e esse devir outro não pode ser prescritivo nem se organizar em função de uma norma identitária, de modo que só se organizará em função de uma estética da existência.

\section{Referências}

Althusser, L. (1993). Freud et Lacan. In Écrits sur la psychanalyse (pp. 22-53). Paris, França: Stock, Imec. (Trabalho original publicado em 1964).

Birman, J. (1997). Estilo e modernidade em psicanálise. São Paulo, SP: Ed. 34.

Birman, J. (1999). Cartografias do feminino. São Paulo, SP: Ed. 34.

Birman, J. (2001). Gramáticas do erotismo. A feminilidade e as suas formas de subjetivação em psicanálise. Rio de Janeiro, RJ: Civilização Brasileira.

Birman, J. (2018, jan./jun.). Sexualidade na contemporaneidade. Cadernos de psicanálise, 40(38), 137-159.

Butler, J. (1987). Subjects of Desire: Hegelian Reflections in Twentieth-Century. New Iorque, NY: Columbia University Press. 


\section{ARTIGOS}

Butler, J. (1999). Gender Trouble: Feminism and the Subversion of Identity. New Iorque, NY: Routledge. (Trabalho original publicado em 1990).

Butler, J. (2004). Precarious Life: The Powers of Mourning and Violence. New Iorque, NY: Verso.

Butler, J. (2005). Giving an Account of Oneself. New York, NY: Fordham University Press.

Deleuze, G., \& Guattari, F. (1972). Capitalisme et schizophrénie I. L'anti-CEdipe. Paris, França: Minuit.

Derrida, J. (1967). De la grammatologie. Paris, França: Minuit.

Foucault, M. (1972). Histoire de la folie à l'âge classique. Paris, França: Gallimard.

Foucault, M. (1975). Surveiller et punir: naissance de la prison. Paris, França: Gallimard.

Foucault, M. (1976). Histoire de la sexualité I. La volonté de savoir. Paris, França: Gallimard.

Foucault, M. (1994a). La société punitive. In Dits et écrits (vol. II, pp. 456-470). Paris, França: Gallimard. (Trabalho original publicado em 1973).

Foucault, M. (1994b). Les rapports de pouvoir passent à l'intérieur des corps. In Dits et écrits (vol. III, pp. 228-236). Paris, França: Gallimard. (Trabalho original publicado em 1977).

Foucault, M. (1994c). Nietzsche, la généalogie, l'histoire. In Dits et écrits (vol. II, pp. 136-156). Paris, França: Gallimard. (Trabalho original publicado em 1971).

Foucault, M. (1997). Il faut défendre la société. Paris, França: Gallimard, Seuil. (Trabalho original publicado em 1975-1976).

Foucault, M. (2000). Naissance de la clinique. Paris, França: PUF. (Trabalho original publicado em 1963).

Foucault, M. (2001). L’herméneutique du sujet. Paris, França: Gallimard, Seuil. (Trabalho original publicado em 1981-1982).

Foucault, M. (2011). The Gay Science. Critical Inquiry, 37(3), 385-403. (Trabalho original publicado em 1978).

Foucault, M. (2015). Qu'est-ce que la critique?, suivi de La culture de soi. Paris, França: Vrin (Trabalho original publicado em 1983).

Freud, S. (1988a). Le refoulement. In Euvres completes (Vol. 13, pp. 187-201). Paris, França: PUF. (Trabalho original publicado em 1915).

Freud, S. (1988b). Pulsions et destins des pulsions. In Euvres completes (Vol. 13, pp. 161-185). Paris, França: PUF. (Trabalho original publicado em 1915).

Freud, S. (1999). Analyse d'une phobie chez un petit garçon de 5 ans (Le petit Hans). In Cinq psychanalyses (pp. 93-198). Paris, França: PUF. (Trabalho original publicado em 1909).

Freud, S. (2002a). La disparition du complexe d'CEdipe. In La vie sexuelle (pp. 117-122). Paris, França: PUF. (Trabalho original publicado em 1923) 
R E V V I $S$ S T A

LATINOAMERICANA

DE PSICOPATOLOGIA

F U N D M E N T A L

Freud, S. (2002b). L’organisation génitale infantile. In La vie sexuelle (pp. 113-116). Paris, França: PUF. (Trabalho original publicado em 1923).

Freud, S. (2002c). Quelques conséquences psychiques de la différence anatomique entre les sexes. In La vie sexuelle (pp. 123-132). Paris, V: PUF. (Trabalho original publicado em 1925).

Freud, S. (2004). Nouvelle suite des leçons d'introduction à la psychanalyse. In Ouvres complètes (Vol. 19, pp. 83-268), Paris, V: PUF. (Trabalho original publicado em 1933).

Freud, S. (2005a). Contribution à l'histoire du mouvement psychanalytique. In Euvres complètes (Vol. 7, pp. 247-315). Paris, França: PUF. (Trabalho original publicado em 1914).

Freud, S. (2005b). La morale sexuelle ‘culturelle' et la nervosité moderne. In Euvres complètes (Vol. 8, pp. 195-219). Paris, França: PUF. (Trabalho original publicado em 1908).

Freud, S. (2006). Trois essais sur la vie sexuelle. In Euvres complètes (Vol. 6, pp. 59-181). Paris, França: PUF. (Trabalho original publicado em 1905).

Freud, S. (2010a). Les psychonévroses de défense. In Névrose, psychose et perversion (pp. 1-14). Paris, França: PUF. (Trabalho original publicado em 1894).

Freud, S. (2010b). Nouvelles remarques sur les psychonévroses de défense. In Névrose, psychose et perversion (pp. 61-81). Paris, França: PUF. (Trabalho original publicado em 1896).

Freud, S. (2010c). Névrose et psychose. In Névrose, psychose et perversion (pp. 283-286). Paris, França: PUF. (Trabalho original publicado em 1924).

Freud, S. (2010d). La perte de la réalité dans la névrose et psychose. In Névrose, psychose et perversion (pp. 299-303). Paris, França: PUF. (Trabalho original publicado em 1924).

Freud, S. (2010e). L'analyse finie et l'analyse infinie. In Euvres complètes (Vol. 20, pp. 13-55). Paris, França: PUF. (Trabalho original publicado em 1937).

Freud, S., \& Breuer, J. (2002). Études sur l'hystérie. Paris, França: PUF. (Trabalho original publicado em 1885).

Lacan, J. (1966a). L'instance de la lettre dans l'inconscient ou la raison depuis Freud. In Écrits (pp. 493-529). Paris, França: Seuil. (Trabalho original publicado em 1957).

Lacan, J. (1966b). Subversion du sujet et dialectique du désir. In Écrits (pp. 793-827). Paris: Seuil. (Trabalho original publicado em 1960).

Lacan, J. (1966c). La science et la vérité. In Écrits (pp. 855-877). Paris: Seuil.

Lacan. J. (1966d). Fonction et champ de la parole et du langage en psychanalyse. In Écrits (pp. 237-321). Paris: Seuil. (Trabalho original publicado em 1953).

Lacan, J. (1966e). D'une question préliminaire à tout traitement possible de la psychose. In Écrits (pp. 531-583). Paris, França: Seuil. (Trabalho original publicado em 1958). 


\section{ARTIGOS}

Lacan, J. (1973). Le séminaire. Livre XI. Les quatre concepts fondamentaux de la psychanalyse. Paris, França: Seuil. (Trabalho original publicado em 1964).

Lacan, J. (1975) Le séminaire. Livre XX. Encore. Paris, França: Seuil (Trabalho original publicado em 1972-1973).

Lacan, J. (1981). Le séminaire. Livre III. Les psychoses. Paris, França: Seuil. (Trabalho original publicado em 1955-1956).

Lacan, J. (1986). Le séminaire. Livre VII. L'éthique de la psychanalyse. Paris, França: Seuil. (Trabalho original publicado em 1959-1960).

Lacan, J. (1987). Joyce le symptôme II. In J. Aubert (Org.), Joyce avec Lacan (pp. 31-36). Paris, França: Navarin, 1987. (Trabalho original publicado em 1979).

Lacan, J. (1991). Le séminaire. Livre XVII. L'envers de la psychanalyse. Paris, França: Seuil. (Trabalho original publicado em 1969-1970).

Lacan, J. (1998). Le séminaire. Livre X. Les formations de l'inconscient. Paris, França: Seuil. (Trabalho original publicado em 1957-1958).

Lacan, J. (2005). Le séminaire. Livre XXIII. Le sinthome. Paris, França: Seuil (Trabalho original publicado em 1975-1976).

Lacan, J. (2011) Le séminaire. Livre XIX. ...ou pire. Paris, França: Seuil (Trabalho original publicado em 1971-1972).

Poli, M. C. (2007). Feminino/Masculino. A diferença sexual em psicanálise. Rio de Janeiro, RJ: Zahar.

\section{Resumos}

(Sexuality, gender and identity: questions for psychoanalysis)

This paper aims to analyze in what way the notions of sexuality, gender and identity pose questions to psychoanalysis, as they problematize forms of subjectivation present in their discursive practice. Taking into account Foucault's analysis of the formation of the device of sexuality and Butler's discussion on the problem of identity in gender discussions, we intend to situate the place of the Oedipus complex in the constitution of the subject in psychoanalysis and Freud's critique of the moralization of sexuality in modern experience. To conclude, based on the notions of vulnerability and dispossession of the self, we revisit the psychoanalytic concepts of helplessness and femininity to reflect on the importance of a thinking on otherness for psychoanalytic practice.

Key words: Sexuality, genre, identity, otherness 
(Sexualité, genre et identité : questions à la psychanalyse)

Le but de cet article est d'analyser la façon dont les notions de sexualité, de genre et d'identité posent des questions à la psychanalyse, dans la mesure où elles problématisent les formes de subjectivation présentes dans sa pratique discursive. En considérant l'analyse de Foucault sur la formation du dispositif de la sexualité et la discussion de Butler sur le problème de l'identité dans les discussions sur le genre, nous avons l'intention de situer la place du complexe d'Edipe dans la constitution du sujet dans la psychanalyse et la critique de Freud à la moralisation de la sexualité dans l'expérience moderne. Enfin, à partir des notions de vulnérabilité et de dépossession de soi, les concepts psychanalytiques de détresse et de féminité sont abordés dans le but de réfléchir à l'importance d'une pensée d'altérité pour la pratique psychanalytique.

Mots clés: Sexualité, genre, identité, altérité

(Sexualidad, género e identidad: cuestiones para el psicoanálisis)

El objetivo de este ensayo es analizar la forma en la que las nociones de sexualidad, género e identidad plantean cuestiones para el psicoanálisis, en la medida en que problematizan formas de subjetivación presentes en su práctica discursiva. Considerando el análisis de Foucault sobre la formación del dispositivo de la sexualidad, y la discusión iniciada por Butler sobre el problema de la identidad en las discusiones de género, se pretende situar el lugar del complejo de Edipo en la constitución del sujeto en el psicoanálisis y la crítica de Freud a la moralización del sujeto en la experiencia moderna. Finalmente, a partir de las nociones de vulnerabilidad y de desposesión de sí, se reanudan los conceptos psicoanalíticos de desamparo y de femineidad con el objetivo de pensar la importancia de un pensamiento de la alteridad para la práctica psicoanalítica.

Palabras clave: Sexualidad, género, identidad, alteridad

(Sexualität, Geschlecht und Identität: Fragen an die Psychoanalyse)

Dieser Artikel analysiert auf welche Art und Weise die Begriffe Sexualität, Geschlecht und Identität Fragen an die Psychoanalyse stellen, insoweit als sie die in ihrer diskursiven Praxis vorhandenen Formen der Subjektivierung problematisieren. In Anbetracht der Analyse von Foucault über die Entstehung des Sexualitätsdispositives und Butlers Diskussion des Identitätsproblems in der Genderdiskussion versuchen wir den Platz des Ödipus-Komplexes in der Konstitution des Subjekts in der Psychoanalyse zu erörtern, sowie die Kritik Freuds an die Moralisierung der Sexualität in der modernen Erfahrung. Zum Schluss greifen wir aufgrund der Begriffe Verwundbarkeit und Enteignung des Selbst die psychoanalytischen Konzepte des Aufhebens und der Weiblichkeit erneut auf, um die Bedeutung der Alterität für die psychoanalytische Praxis zu erwägen.

Schlüsselwörter: Sexualität, Geschlecht, Identität, Alterität 


\section{ARTIGOS}

Citação/Citation: Leitão Martins, L. P. (2019, junho). Sexualidade, gênero e identidade: questões para a psicanálise. Revista Latinoamericana de Psicopatologia Fundamental, 22(2), 215-237. http://dx.doi.org/10.1590/1415-4714.2019v22n2p215-4.

Editoras/Editors: Profa. Dra. Ana Maria R. G. Oda e Profa. Dra. Sonia Leite

Submetido/Submitted: 1.12.2018 / 12.1.2018 Aceito/Accepted: 31.1 .2019 / 1.31.2019

Copyright: (C) 2009 Associação Universitária de Pesquisa em Psicopatologia Fundamental/ University Association for Research in Fundamental Psychopathology. Este é um artigo de livre acesso, que permite uso irrestrito, distribuição e reprodução em qualquer meio, desde que o autor e a fonte sejam citados / This is an open-access article, which permits unrestricted use, distribution, and reproduction in any medium, provided the original authors and sources are credited.

Financiamento/Funding: Este trabalho não recebeu apoio / This work received no funding.

Conflito de interesses/Conflict of interest: $\mathrm{O}$ autor declara que não há conflito de interesses ./ The authors declare that there is no conflict of interest.

\section{Luiz Paulo Leitão Martins}

Pesquisador associado ao Centre de Recherches Psychanalyse, Médecine et Société (Paris, França). Professor ATER no Departamento de Psicologia Clínica da Universidade Toulouse 2 (Toulouse, França). Psicanalista, membro do Espaço Brasileiro de Estudos Psicanalíticos (Rio de Janeiro, RJ, Br).

Université Paris Diderot - UFR d'Études Psychanalytiques

Bât. Olympe de Gouges

8 rue Albert-Einstein

75013 Paris, França

https://orcid.org/0000-0003-4242-7056

luizpaulo.1martins@gmail.com

This is an open-access article, which permits unrestricted use, distribution, and reproduction in any medium for non-commercial purposes provided the original authors and sources are credited. 